\title{
Treatment results of gastrointestinal perforation after endoscopic retrograde cholangiopancreatography
}

\author{
Tomasz Miłek, Piotr Ciostek, Piotr Porzycki, Magdalena Kwiatkowska \\ I Division I Department of General and Vascular Surgery, Medical University of Warsaw, Poland
}

Prz Gastroenterol 2013; 8 (5): 299-304

DOI: $10.5114 / p g .2013 .38732$

Key words: retrograde cholangiopancreatography, gastrointestinal perforation.

Address for correspondence: Tomasz Mitek MD, PhD, I Division I Department of General and Vascular Surgery, Medical University of Warsaw, 8 Kondratowicza St, 03-242 Warsaw, Poland, phone: +48 604422 345, e-mail: tomasz_milek@wp.pl

\begin{abstract}
Introduction: Duodenal perforation, damage to common bile duct or ampulla of Vater complicates from $0.7 \%$ to $10 \%$ of endoscopic retrograde cholangiopancreatography (ERCP) procedures. This complication is associated with high risk of contracting fatal diseases and death. As the endoscopic and minimally invasive treatment methods develop and gain popularity, it becomes increasingly important to determine the correct procedure in the event of gastrointestinal perforation after ERCP.

Aim: To present the results of treatment of gastrointestinal perforation after ERCP and indicate the correct procedure for such cases.

Material and methods: The material includes 19 patients who underwent ERCP in the years 2008-2011 and were subsequently diagnosed with duodenal perforation (except for duodenal bulb) and common bile duct (CBD). Women accounted for $68 \%$ of patients (13/19), while men constituted 32\% (6/19). The mean age of patients was 66.6 years old. Indications for ERCP included cholelithiasis in $95 \%$ of cases and bile duct strictures in the remaining $5 \%$. Treatment was conditional on the result of X-ray examination of the abdominal cavity, followed by computed tomography with aqueous contrast medium administered orally.

Results: Four patients were diagnosed with intraperitoneal perforation and 15 patients with retroperitoneal perforation. In the patient group with retroperitoneal perforation the contrast media leakage (10 patients) required surgical intervention - the perforation site was located in 5 cases; in the other 5 the site could not be found. With the absence of active contrast media leakage in computed tomography (CT) (5 patients) conservative treatment was applied. Four patients with intraperitoneal perforation were referred for operative treatment. In patients under conservative treatment no complications were observed and the average hospitalization time was 9 days. Among patients with retroperitoneal perforation, who had undergone surgical treatment, complications occurred in 3 cases. The average hospitalization time in the group in which the perforation site was located was 16 days, while in the group with an unidentified perforation site it was 17 days. Patients with intraperitoneal perforation were given operative treatment, with the average hospitalization time of 12 days.

Conclusions: Each patient with suspected post-ERCP perforation should undergo CT of the abdominal cavity with aqueous contrast medium administered orally. In the event of no contrast leak in patients with retroperitoneal duodenal perforation, conservative treatment should be applied. In the case of retroperitoneal perforation with active contrast media leakage outside the gastrointestinal tract, and in the case of intraperitoneal perforation, an immediate surgical intervention is recommended.
\end{abstract}

\section{Introduction}

Endoscopic procedures are currently counted among the basic diagnostic and therapeutic methods for various gastrointestinal tract diseases.

The procedures are generally recognized as safe, although one must bear in mind that endoscopic treatments are minimally invasive procedures and, like all treatments of this group, may involve the risk of complications, including severe ones. Endoscopic retrograde cholangiopancreatography (ERCP) and endoscopic sphincterotomy (ES) are characterized by a high degree of performance difficulty. Nevertheless, complications occur only in $5-10 \%$ of cases $[1,2]$.

It is of paramount importance, when alarming symptoms after ERCP occur, to begin the diagnostic process and start appropriate therapy as soon as possible.

Complications arising from endoscopic procedures can be categorized into non-specific (general) and specific (characteristic for the given treatment). The term 'general complications' is understood as complications with no direct relation to the given medical procedure, 
but which are correlated with the general condition and other diseases of the patient (e.g. heart diseases, arterial hypertension) [3]. Such complications are a frequent cause of death in the perioperative period and can be reduced by such simple measures as proper patient qualification and preparation.

However, this paper will focus on the rare, but very dangerous, specific complication of duodenal perforation [4].

\section{Aim}

The aim of the study was to present the results of our own treatments of post-ERCP duodenal perforation and propose a standard procedure for such cases.

\section{Material and methods}

The material includes 19 patients who in the years 2008-2011 were diagnosed with gastrointestinal perforation as a post-ERCP complication. The analyzed group comprised 13 women and 6 men. The mean age of the patients was 66.6 years old (45-75) (Table I). The patients with suspected perforation (usually intensifying abdominal pain after ERCP) underwent preliminary diagnostics, i.e. overview X-ray of the abdominal cavity. If the $X$-ray examination revealed perforation symptoms (air under the diaphragm or in the retroperitoneum), computed tomography (CT) of the abdominal cavity was performed with orally administered aqueous contrast medium. In the event of symptoms of active contrast medium leakage, the patient was referred for surgical intervention. If no contrast medium leakage was observed, conservative therapy was applied.

\section{Results}

Retroperitoneal perforation was diagnosed in 15 patients, of whom 10 underwent surgery. The retroperitoneal perforation sites were located in only 5 laparotomies - in 4 cases the perforation occurred in the duodenum and in 1 case in the common bile duct (CBD). In the case of duodenal perforation, the damage site was sutured, while in the bile duct perforation the Kehr's drain was applied. No postoperative complications occurred in this group. The average hospitalization time was 16 days. In other patients who had undergone surgery $(5 / 10)$ the perforation site could not be located. However, mass yellow coloration of tissues in retroperitoneum was observed, which suggested microperforation of the main bile duct. In this case only an abdominal cavity drain was applied. Postoperative complications occurred in 3 patients, taking the form of: surgical wound suppuration (on the $4^{\text {th }}$ day after the operation), acute pancreatitis (on the $2^{\text {nd }}$ day) and pneumonia (on the $7^{\text {th }}$ day), which considerably prolonged hospitalization time. In this group the average hospitalization time was 17 days. In the patient with acute pancreatitis parenteral alimentation was applied.

Five patients, who were diagnosed with retroperitoneal perforation on the basis of the X-ray image of the abdominal cavity, but in whom no contrast media leakage was observed in CT with orally administered contrast medium, received conservative therapy.

Four patients were diagnosed with intraperitoneal perforation. In each case the perforation concerned the duodenal bulb. During the laparotomy the perforation site was sutured. The hospitalization of those patients was not interrupted by any complications and lasted 12 days on average.

\section{Discussion}

Endoscopic retrograde cholangiopancreatography is a recognized diagnostic and therapeutic method for various diseases of bile ducts and pancreas. However, together with endoscopic sphincterotomy, ERCP is one of the more technically complicated procedures in gastrointestinal endoscopy. Currently ERCP is seldom used only for diagnostic purposes; usually it is accompanied by therapeutic activities that considerably increase the degree of difficulty and risk level of the procedure [2]. In spite of that, severe complications are not frequent, occurring in approx. $5-10 \%$ of cases, of which $0.5-0.7 \%$ are fatal $[1,2]$.

Specific ERCP complications include acute pancreatitis, gastrointestinal bleeding, perforations, acute cholangitis and cholecystitis.

Perforations in the course of ERCP occur in approx. $1 \%$ of cases and the mortality rate can be as high as $18 \%$. Thus, it is a rare complication but with a high death rate [5].

The procedure to follow in the case of ERCP perforation raises much controversy and contradictory opinions. It remains unresolved whether the patient benefits more from delaying the surgical intervention and applying conservative therapy as long as possible, or administering operative treatment immediately, thus exposing them to all the consequences of surgery.

The "traditional" approach, supported by some authors, advocates immediate surgical intervention [6, 7]. However, there are an increasing number of reports on successful conservative therapy [8-11]. The choice of procedure in the case of post-ERCP perforation depends on the mechanism and location of the damage, which are the basis of most classifications. However, there are other factors to consider: clinical image and the results of imaging and laboratory examinations, which are often the decisive factor concerning the future course of action or prognosis. 
Table I. Classfication of patients

\begin{tabular}{|c|c|c|c|c|c|c|c|c|c|}
\hline Item & Gender & $\begin{array}{c}\text { Age } \\
\text { [years] }\end{array}$ & $\begin{array}{l}\text { Original } \\
\text { disease }\end{array}$ & $\begin{array}{l}\text { CT with } \\
\text { contrast }\end{array}$ & $\begin{array}{l}\text { Perforation } \\
\text { site }\end{array}$ & $\begin{array}{l}\text { Perforation } \\
\text { type }\end{array}$ & Treatment & $\begin{array}{l}\text { Complications } \\
\text { during } \\
\text { hospitalization }\end{array}$ & $\begin{array}{l}\text { Hospitalization } \\
\text { time [days] }\end{array}$ \\
\hline 1 & $\mathrm{~F}$ & 45 & $\begin{array}{l}\text { Bile duct } \\
\text { stricture }\end{array}$ & Leakage & Not found & I & Laparotomy & $\begin{array}{c}\text { Acute } \\
\text { pancreatitis on } \\
2^{\text {nd }} \text { day after } \\
\text { surgery }\end{array}$ & 26 \\
\hline 2 & $\mathrm{~F}$ & 65 & Cholelithiasis & Leakage & Not found & I & Laparotomy & $\begin{array}{c}\text { No } \\
\text { complications }\end{array}$ & 12 \\
\hline 3 & M & 67 & Cholelithiasis & Leakage & $\begin{array}{l}\text { Duodenal } \\
\text { bulb }\end{array}$ & $\|$ & $\begin{array}{c}\text { Laparotomy, } \\
\text { perforation } \\
\text { suturing }\end{array}$ & $\begin{array}{c}\text { No } \\
\text { complications }\end{array}$ & 12 \\
\hline 4 & M & 75 & Cholelithiasis & Leakage & $\begin{array}{l}\text { Duodenal } \\
\text { bulb }\end{array}$ & II & $\begin{array}{l}\text { Laparotomy, } \\
\text { perforation } \\
\text { suturing }\end{array}$ & $\begin{array}{c}\text { No } \\
\text { complications }\end{array}$ & 14 \\
\hline 5 & $\mathrm{~F}$ & 60 & Cholelithiasis & No leakage & $x$ & I & Conservative & $\begin{array}{c}\text { No } \\
\text { complications }\end{array}$ & 7 \\
\hline 6 & $\mathrm{~F}$ & 71 & Cholelithiasis & Leakage & $\begin{array}{l}\text { Duodenal } \\
\text { wall }\end{array}$ & 1 & $\begin{array}{l}\text { Laparotomy, } \\
\text { perforation } \\
\text { suturing }\end{array}$ & $\begin{array}{c}\text { No } \\
\text { complications }\end{array}$ & 13 \\
\hline 7 & $\mathrm{~F}$ & 62 & Cholelithiasis & No leakage & $x$ & I & Conservative & $\begin{array}{c}\text { No } \\
\text { complications }\end{array}$ & 9 \\
\hline 8 & M & 65 & Cholelithiasis & Leakage & Not found & I & Laparotomy & $\begin{array}{l}\text { Surgical wound } \\
\text { suppuration }\end{array}$ & 17 \\
\hline 9 & M & 75 & Cholelithiasis & Leakage & $\begin{array}{l}\text { Duodenal } \\
\text { wall }\end{array}$ & 1 & $\begin{array}{l}\text { Laparotomy, } \\
\text { perforation } \\
\text { suturing }\end{array}$ & $\begin{array}{c}\text { No } \\
\text { complications }\end{array}$ & 14 \\
\hline 10 & $\mathrm{~F}$ & 73 & Cholelithiasis & Leakage & Not found & 1 & Laparotomy & Pneumonia & 20 \\
\hline 11 & $\mathrm{~F}$ & 69 & Cholelithiasis & Leakage & Not found & 1 & Laparotomy & $\begin{array}{c}\text { No } \\
\text { complications }\end{array}$ & 12 \\
\hline 12 & M & 65 & Cholelithiasis & No leakage & $x$ & 1 & Conservative & $\begin{array}{c}\text { No } \\
\text { complications }\end{array}$ & 11 \\
\hline 13 & $\mathrm{~F}$ & 58 & Cholelithiasis & No leakage & $x$ & 1 & Conservative & $\begin{array}{c}\text { No } \\
\text { complications }\end{array}$ & 9 \\
\hline 14 & $\mathrm{~F}$ & 63 & Cholelithiasis & Leakage & $\begin{array}{l}\text { Duodenal } \\
\text { bulb }\end{array}$ & II & $\begin{array}{l}\text { Laparotomy, } \\
\text { perforation } \\
\text { suturing }\end{array}$ & $\begin{array}{c}\text { No } \\
\text { complications }\end{array}$ & 11 \\
\hline 15 & $\mathrm{~F}$ & 72 & Cholelithiasis & No leakage & $x$ & I & Conservative & $\begin{array}{c}\text { No } \\
\text { complications }\end{array}$ & 9 \\
\hline 16 & $\mathrm{~F}$ & 75 & Cholelithiasis & Leakage & $\begin{array}{l}\text { Duodenal } \\
\text { wall }\end{array}$ & I & $\begin{array}{l}\text { Laparotomy, } \\
\text { perforation } \\
\text { suturing }\end{array}$ & $\begin{array}{c}\text { No } \\
\text { complications }\end{array}$ & 15 \\
\hline 17 & $\mathrm{~F}$ & 65 & Cholelithiasis & Leakage & $\begin{array}{l}\text { Duodenal } \\
\text { bulb }\end{array}$ & ॥ & $\begin{array}{l}\text { Laparotomy, } \\
\text { perforation } \\
\text { suturing }\end{array}$ & $\begin{array}{c}\text { No } \\
\text { complications }\end{array}$ & 11 \\
\hline 18 & M & 71 & Cholelithiasis & Leakage & $C B D$ & I & $\begin{array}{l}\text { Laparotomy, } \\
\text { Kehr's drain }\end{array}$ & $\begin{array}{c}\text { No } \\
\text { complications }\end{array}$ & 23 \\
\hline 19 & $\mathrm{~F}$ & 69 & Cholelithiasis & Leakage & $\begin{array}{l}\text { Duodenal } \\
\text { wall }\end{array}$ & I & $\begin{array}{l}\text { Laparotomy, } \\
\text { perforation } \\
\text { suturing }\end{array}$ & $\begin{array}{c}\text { No } \\
\text { complications }\end{array}$ & 14 \\
\hline
\end{tabular}


In the classification proposed by Howard et al. [12] and Stapfer et al. [5] perforations are divided by type according to the origin and location. Cotton et al. [1], on the other hand, focused mainly on the mechanism of perforation. Based on the expertise and experience of the aforementioned authors and on our own, we have drawn up our classification, focusing only on the location of damage in the duodenum and the structures in its immediate vicinity (CBD). We have not considered remote damage, such as gullet perforations or perforations caused by a migrating stent, since such complications are extremely rare and we have not yet come across such cases in our department.

Perforations occurring during ERCP can be divided into two main groups: extra- and intraperitoneal. Perforations in the extraperitoneal group (type I) include duodenal perforations (except for the duodenal bulb), CBD and ampulla of Vater. Intraperitoneal perforations (type II) include only perforations of the duodenal bulb. Concerning the procedure for perforation, a general rule of thumb has been adopted that patients with suspected (after control X-ray examination) perforation who additionally show clinical symptoms (usually intensifying abdominal pain) should immediately undergo CT of the abdominal cavity with orally administered aqueous contrast medium. If the administered contrast medium gathers in the extra- or intraperitoneal space, it is an indication for immediate surgical intervention. If no such gathering is visible, the surgery is not applied. In the latter case the patient receives conservative therapy according to the NBM - nothing by mouth - rule, i.e. taking anything orally is prohibited, IV administration of fluids and antibiotics, and also parenteral alimentation if needed (Table II).

The majority of perforations are type I, related to the retroperitoneal duodenal wall, ampulla of Vater or bile ducts. Damage usually occurs during sphincterotomy, as well as during use of other endoscopy tools, such as retrieval baskets, guidewires, etc. Other risk factors include previous procedures of this kind, sphincter of Oddi dysfunction (SOD), as well as sphincter cut "at 1-2 o'clock". Interestingly, patients with cholelithiasis are less susceptible to perforation, which is probably due to the thickening of the bile duct wall caused by irritation by gallstones (concrements) [1]. Also, the examiner's experience (number of performed procedures)

Table II. Classification of perforations

\begin{tabular}{cl}
$\begin{array}{c}\text { Extraperitoneal } \\
\text { (type I) }\end{array}$ & Duodenum (except for duodenal bulb) \\
\cline { 2 - 2 } & Common bile duct \\
\hline $\begin{array}{c}\text { Intraperitoneal } \\
\text { (type II) }\end{array}$ & Duodenal bulb \\
\hline
\end{tabular}

[4] has proven insignificant - young endoscopists make errors due to inexperience, older ones due to routine.

Type I perforations usually constitute minor damage. Sometimes the endoscopist is able to identify such perforations already during the endoscopy procedure. When performing the gastrointestinal endoscopy, endoscopists should pay attention to unexpected structures, contrast around the duodenum or "strange" non-anatomical shapes [1]; such situations should arouse their concern.

However, if perforation is not identified during the procedure, the alarming symptom occurring shortly after endoscopy is rapid deterioration of the patient's general condition, with intensifying abdominal pain. In the case of retroperitoneal perforations, though, the clinical image often does not correspond to the patient's true condition. This is related to the specific nature of retroperitoneal perforations, which are characterized by a relatively atypical, often imprecise clinical image that may somewhat obscure the severity of symptoms.

It should be borne in mind, however, that early symptoms by their very nature may be uncharacteristic and the differential diagnostics must always take into consideration the most typical reasons for the given condition of the patient. Therefore, in the case of e.g. abdominal symptoms occurring shortly after the endoscopy, the first complication to consider should be the most frequent one, namely acute pancreatitis [4, 20].

If perforation is suspected, one of the key, if not the crucial factor determining further prognosis is the time between the occurrence of damage and the identification and beginning of effective therapy.

Perforations should always be suspected if [1]:

- the patient complains about pain that occurs shortly after the procedure (pancreatitis usually develops within 4-12 $\mathrm{h}$ after treatment),

- the pain is acute and intensifies rapidly,

- the abdominal pain is accompanied by voluntary guarding and tachycardia,

- within several hours after the procedure symptoms of pneumoderma, pneumomediastinum or pneumothorax occur $[13,14]$,

- laboratory tests indicate increasing WBC (this is not a very precise indicator, similarly to the increase of amylase or lipase in blood serum).

The next stage of diagnostics should be X-ray examination of the abdominal cavity or, preferably, computed tomography of the abdominal cavity, which is a much more sensitive method $[15,16]$.

Detection of air in the retroperitoneal space in X-ray or CT examination of the abdominal cavity should be an indication for immediate surgical intervention, since sometimes air in the retroperitoneal space after ERCP 
occurs in patients who otherwise exhibit no clinical symptoms, thus becoming the decisive factor for surgical treatment. Wu et al. [17] in their report suggest that the presence of air in the retroperitoneal space in patients without symptoms or with mild pain symptoms may be related to the large volume of air used to open up the lumen of the gastrointestinal tract. Wu provides examples of patients receiving conservative therapy in whom, after control CT examination, the air volume was found to decrease. However, if the CT examination of the abdominal cavity with orally administered contrast medium reveals leakage of the contrast medium into the retroperitoneal space, this should be an indication for immediate surgical intervention [10]. Also, there is no consent as to the recommended procedure in the event of identifying fluid collections in the patient, but without active leakage of contrast medium during CT. Some reports suggest that identifying fluid collections on the CT image is an unfavorable prognostic factor and should be an indication for surgery in its own right [5, $15,18]$. However, further research is required to provide a unanimous answer to this problem. At the moment, the authors of this paper believe that identifying any fluid collections on the CT image is an indication for operative treatment, especially given the fact that in the case of perforation located e.g. in the bile duct after the stationary phase (without leakages) there is a risk of bile spillage from the perforation site, thus expanding the fluid area.

If the CT image identifies only air and no active leakage, we believe that conservative therapy should be the treatment of choice. One argument for this view may be the fact that perforations are often very small and close by themselves, and during laparotomy it is often impossible to identify the perforation site $[5,17]$.

However, considering the damage to the common bile duct, we believe that each case of such perforation requires at least decompression of the bile duct and dressing with a drain, stent or prosthesis. The opinion voiced by Dunham et al. [19], who suggest that implementing a stent into the bile duct may affect the healing of the perforation due to the presence of a foreign body (i.e. the stent) and therefore it should not be used, seems controversial. However, as experience shows, complications related to bile leakage into the peritoneal cavity or into the retroperitoneal space are much more dangerous to the patient's life and health than prolonged healing of the perforation.

Type I perforations, related to damage of the duodenal wall remote from the ampulla of Vater and usually caused by too rapid maneuvering of the endoscope, are mostly large enough to eliminate any diagnostic doubt. Moreover, those perforations are usually identified al- ready during the endoscopic procedure [5]. In such cases there is no doubt that surgery is the correct course of action. Type II perforations - intraperitoneal, characterized by the presence of air under the diaphragmatic dome and/or identifying leakage of contrast medium into the peritoneal cavity - always require immediate surgical intervention.

Duodenal perforations are post-ERCP complications that, although rare, have a very high death rate [20]. In the case of retroperitoneal perforation the preferred treatment method is subject to some discussion, especially if the patient does not exhibit any visible clinical symptoms. Further course of treatment depends on the $\mathrm{CT}$ image of the abdominal cavity with orally administered contrast medium. There is no universal consent as to the correct procedure in the event of a fluid collection visible on the $\mathrm{CT}$ image, but without properties of active contrast medium leakage. Perhaps one solution might be to wait and monitor whether the fluid collection is expanding. However, there has been no research to date to confirm or dismiss this theory.

\section{Conclusions}

In each case of suspected gastrointestinal perforation it is recommended to apply CT of the abdominal cavity with orally administered aqueous contrast medium. In the event of no contrast medium leakage in the $\mathrm{CT}$ in patients with perforation of the duodenum, ampulla of Vater or bile duct, the best available treatment is conservative therapy. In the case of retroperitoneal perforation with documented contrast media leakage outside the gastrointestinal tract, and in the case of intraperitoneal perforation, an urgent surgical intervention is recommended.

\section{References}

1. Cotton PB, Leung JW. Advanced digestive endoscopy: ERCP. Wiley-Blackwell 2005.

2. Boduła A, Pazurek M, Woźniak B, et al. Comparison of magnetic resonance cholangiopancreatography and endoscopic retrograde cholangiopancreatography in the diagnosis of pancreatobiliary diseases. Prz Gastroenterol 2011; 6: 187-94.

3. Jałocha $t$, Wojtuń S, Gil J. The frequency and methods of preventing complication of gastrointestinal endoscopic procedures. Pol Merk Lek 2007; 131: 495-8.

4. Piotrowska-Staworko A, Świdnicka-Siergiejko A., Baniukiewicz A, et al. Complication after endoscopic retrograde cholangiopancreatography. Gastoenterol Pol 2007; 14: 307-12.

5. Stapfer M, Selby RR, Stain SC, et al. Management of duodenal perforation after endoscopic retrograde cholangiopancreatography and sphincterotomy. Ann Surgery 2000; 232: 191-8.

6. Booth FV, Doerr RJ, Khalafi RS, et al. Surgical management of complications of endoscopic sphincterotomy with precut papillotomy. AmJ Surg 1990; 159: 132-5. 
7. Mustard R Jr, Mackenzie R, Jamieson C, et al. Surgicalcomplications of endoscopic sphincterotomy. Can J Surg 1984; 27: 215-7.

8. Scarlett PY, Falk GL. The management of perforation of the duodenum following endoscopic sphincterotomy: a proposal for selective therapy. Aust N Z J Surg 1994; 64: 843-6.

9. Dunham F, Bourgeois N, Gelin M, et al. Retroperitoneal perforations following endoscopic sphincterotomy: clinical course and management. Endoscopy 1982; 14: 92-6.

10. Chung RS, Sivak MV, Ferguson DR. Surgical decisions in the management of duodenal perforation complicating endoscopic sphincterotomy. Am J Surg 1993; 165: 700-3.

11. Fatima J, Baron TH, Topazian MD, et al. Pancreaticobiliary and duodenal perforations after periampullary endoscopic procedures. Arch Surg 2007; 142: 448-55.

12. Howard TJ, Tan T, Lehman GA, et al. Classification and management of perforations complicating endoscopic sphincterotomy. Surgery 1999; 126: 658-65.

13. Savides T, Sherman S, Kadell B, et al. Bilateral pneumothoraces and subcutaneous emphysema after endoscopic sphincterotomy. Gastrointest Endosc 1993; 39: 814.

14. Ciaccia D, Branch MS, Baillie J. Pneumomediastinum after endoscopic sphincterotomy. Am J Gastroenterol 1995; 90: 475-7.

15. Zissin R, Shapiro-Feinberg M, Oscadchy A, et al. Retroperitoneal perforation during endoscopic sphincterotomy: imaging findings. Abdom Imaging 2000; 25: 279-82.

16. Gupta R, Reddy DN. Management of complications of GI endoscopy. Indian J Gastroenterol 2006; 25 (Suppl. 1): S29-328.

17. Wu HM, Dixon E, May GR, et al. Management of perforation after endoscopic retrograde cholangiopancreatography (ERCP): a population-based review. HPB (Oxford) 2006; 8: 393-9.

18. Sarr MG, Fishman EK, Milligan FD, et al. Pancreatitis or duodenal perforation after peri-Vaterian therapeutic endoscopic procedures: diagnosis, differentiation and management. Surgery 1986; 100: 461-6.

19. Dunham F, Bourgeois N, Gelin M, et al. Retroperitoneal perforations following endoscopic sphincterotomy: clinical course and management. Endoscopy 1982; 14: 92-6.

20. Matykiewicz J, Głuszek S, Kozieł D. Acute pancreatitis - a complication of endoscopic retrograde cholangiopancreatography. Prz Gastroenterol 2012; 7: 103-7.

Received: 11.03 .2013

Accepted: 3.06 .2013 